\title{
HbxB Is a Key Regulator for Stress Response and $\beta$-Glucan Biogenesis in Aspergillus nidulans
}

\author{
Sung-Hun Son ${ }^{1}$, Mi-Kyung Lee ${ }^{2}$, Ye-Eun Son ${ }^{1}$ and Hee-Soo Park ${ }^{1,3, *(\mathbb{D})}$ \\ 1 School of Food Science and Biotechnology Kyungpook National University, Daegu 41566, Korea; \\ rk05555@naver.com (S.-H.S.); thsdpdms0407@naver.com (Y.-E.S.) \\ 2 Biological Resource Center (BRC), Korea Research Institute of Bioscience and Biotechnology (KRIBB), \\ Jeongeup-si 56212, Korea; miklee1010@kribb.re.kr \\ 3 Department of Integrative Biology, Kyungpook National University, Daegu 41566, Korea \\ * Correspondence: phsoo97@knu.ac.kr; Tel.: +82-53-950-5751
}

Citation: Son, S.-H.; Lee, M.-K.; Son, Y.-E.; Park, H.-S. HbxB Is a Key Regulator for Stress Response and $\beta$-Glucan Biogenesis in Aspergillus nidulans. Microorganisms 2021, 9, 144. https://doi.org/10.3390/ microorganisms 9010144

Received: 10 December 2020 Accepted: 8 January 2021 Published: 11 January 2021

Publisher's Note: MDPI stays neutral with regard to jurisdictional clai$\mathrm{ms}$ in published maps and institutional affiliations.

Copyright: (C) 2021 by the authors. Licensee MDPI, Basel, Switzerland. This article is an open access article distributed under the terms and conditions of the Creative Commons Attribution (CC BY) license (https:// creativecommons.org/licenses/by/ $4.0 /)$.

\begin{abstract}
Homeobox transcription factors are conserved in eukaryotes and act as multi-functional transcription factors in filamentous fungi. Previously, it was demonstrated that $\mathrm{HbxB}$ governs fungal development and spore viability in Aspergillus nidulans. Here, the role of $\mathrm{HbxB}$ in A. nidulans was further characterized. RNA-sequencing revealed that $\mathrm{HbxB}$ affects the transcriptomic levels of genes associated with trehalose biosynthesis and response to thermal, oxidative, and radiation stresses in asexual spores called conidia. A phenotypic analysis found that $h b x B$ deletion mutant conidia were more sensitive to ultraviolet stress. The loss of $h b x B$ increased the mRNA expression of genes associated with $\beta$-glucan degradation and decreased the amount of $\beta$-glucan in conidia. In addition, $h b x B$ deletion affected the expression of the sterigmatocystin gene cluster and the amount of sterigmatocystin. Overall, these results indicated that $\mathrm{HbxB}$ is a key transcription factor regulating trehalose biosynthesis, stress tolerance, $\beta$-glucan degradation, and sterigmatocystin production in A. nidulans conidia.
\end{abstract}

Keywords: conidia; homeobox domain; RNA-sequencing analysis; transcription factor; sterigmatocystin; Aspergillus nidulans

\section{Introduction}

Asexual spores are the main reproductive cells in most filamentous fungi [1,2]. Asexual spores are widespread in environmental niches, survive in harsh conditions, and germinate until appropriate conditions [1]. To survive in aggressive environmental conditions, asexual spores contain protective layers on their cell wall, unlike hyphae [3]. In addition, several signal pathways and regulators are involved in protecting from a myriad of environmental stresses $[4,5]$.

The process of asexual spore production in filamentous fungi has been mainly studied in the model fungus Aspergillus nidulans, as various genetic and molecular techniques have been developed [6,7]. A. nidulans reproduces primarily through asexual development and produces an asexual-specific structure called conidiophore bearing long chains of asexual spores termed as conidia [1]. The process of conidiophore production is regulated by a variety of regulators, such as upstream regulators (FluG and FlbB-E), central regulators (BrlA, AbaA, and WetA), and feedback regulators (VosA and VelB) [8]. For conidia formation and maturation, three transcription factors-Wet A, VosA, and VelB-mainly regulate the mRNA expression of spore-specific and developmental genes [9-14]. These regulators also coordinate the biosynthesis of trehalose, a key component for environmental stress tolerance, and $\beta$-glucan, a key polysaccharide for cell wall integrity $[11,13,15]$. With these transcription factors, several regulators, such as AtfA, VadA, and CatA, are involved in the process of spore tolerance against environmental stresses, maturation, dormancy, and germination [16-20]. 
Homeobox domain-containing proteins are found in animals, plants, yeast, and filamentous fungi $[21,22]$. These proteins contain homeobox DNA-binding motifs and control the transcription of a variety of genes [23,24]. Previous studies have demonstrated that homeobox proteins play diverse roles in fungal growth, differentiation, secondary metabolism, and pathogenesis in several Basidiomycota and Ascomycota [25-27]. For example, mating-type proteins encoded by MATa and MAT $\alpha$ form homocomplexes or heterocomplexes and regulate gene expression and yeast differentiation in the model yeast Saccharomyces cerevisiae [28]. In the pathogenic fungus Candida albicans, GRF10 is involved in filamentous growth, biofilm formation, and virulence [29,30]. In Aspergillus flavus, $\mathrm{Hbx} 1$ plays an important role in fungal differentiation and secondary metabolism [31]. Transcriptomic and phenotypic analyses found that the deletion of $h b x 1$ affects the mRNA expression of developmental genes and secondary metabolite gene clusters [32]. In the human pathogenic fungus Aspergillus fumigatus, $\mathrm{HbxA}$, a homolog of $\mathrm{Hbx1}$, is a key regulator for asexual development, secondary metabolism, and pathogenesis [33].

A recent study indicated that the $A$. nidulans genome contains eight $h b x$ genes [34]. Among these genes, $h b x A$ and $h b x B$ are essential for appropriate hyphal growth, conidiophore production, and cleistothecia formation in $A$. nidulans. In addition, $h b x B$ deletion leads to decreased amounts of trehalose, conidia viability, and thermal tolerance in conidia, implying that $\mathrm{HbxB}$ plays a key role in conidia maturation. To further test the role of $\mathrm{HbxB}$ in conidia, we conducted transcriptomic and phenotypic analyses in this study.

\section{Materials and Methods}

\subsection{Strains and Media}

In this study, control (THS30, pyrG89; AfupyrG ${ }^{+}$) [11], $h b x B$ deletion mutant ( $\triangle h b x B$, TSH1, pyrG89; pyroA4; $\left.\triangle h b x B:: A f u p y r G^{+}\right)$, and $h b x B$-complemented ( $C^{\prime} h b x B$, TSH7, pyrG89; pyroA::hbxB(p):::hbxB:::FLAG $3 x:: p y r o A ; \Delta h b x B:: A f u p y r G^{+}$) [34] strains were used. These fungal strains were grown on minimal medium with $1 \%$ glucose (MMG) for general purpose [35].

\subsection{RNA-Sequencing (RNA-Seq) Analysis}

The whole processes of RNA-seq analysis were performed as described previously [20]. The $\triangle h b x B$ conidia were collected from the plates after 2 days of culture and filtrated through Miracloth (Calbiochem, San Diego, CA, USA). The total RNA from conidia was extracted using Trizol reagent (Invitrogen, Carlsbad, CA, USA). After RNA extraction, DNase I (Promega, Madison, WI, USA) was used for the removal of DNA contamination from RNA samples and then further purification using the RNeasy Mini Kit (Qiagen, Germantown, MD, USA).

Complementary DNA (cDNA) library preparation and RNA-seq were performed by Theragen Bio Co., Ltd. (Seongnam, South Korea). Briefly, mRNA from total RNA was isolated from magnetic beads with oligo(dT). The cDNA library for RNA-seq was prepared using the TruSeq Stranded mRNA Sample Prep Kit (Illumina, San Diego, CA, USA). The library was evaluated using the Agilent High Sensitivity DNA Kit (Agilent Technologies, Santa Clara, CA, USA) and sequenced using an Illumina HiSeq2500 sequencer (Illumina). All RNA-seq data files are available from the National Center for Biotechnology Information BioProject database (PRJNA681980).

RNA-seq data were analyzed as reported previously [20]. Briefly, the filtered readings were mapped onto the A. nidulans A4 transcriptome [36] using the aligner STAR version 2.3.0e software [37]. Gene expression levels were measured using Cufflinks version 2.1.1 [38]. Gene-level count data were generated using the HTSeq-count version 0.5.4p3 tool [39] with the options "-m intersection-nonempty" and "-r option considering paired-end sequence." Differentially expressed genes (DEGs) were identified using the R package TCC [40] on the basis of the read count data. Normalization factors were calculated using the iterative DEGES/edgeR method. DEGs were identified on the basis of a q-value threshold of less than 0.05 . 


\subsection{Gene Ontology (GO) Term Enrichment Analysis}

GO term enrichment analysis was shown using the Gene Ontology Slim Mapper at AspGD [36]. A GO-based trend test was conducted using Fisher's exact test. $p<0.001$ was considered statistically significant to identify the significant category from the analyzed DEGs.

\subsection{Quantitative Reverse Transcription Polymerase Chain Reaction (qRT-PCR) Analysis}

For qRT-PCR analysis, total RNAs from control, $\triangle h b x B$, and $C^{\prime} h b x B$ conidia were extracted using the method mentioned above. The GoScript Reverse Transcription System (Promega) was used for cDNA synthesis. The iTaq Universal SYBR Green Supermix and the CFX96 Touch Real-Time PCR Detection System (both from Bio-Rad, Hercules, CA, USA) were used for qRT-PCR. The $2^{-\Delta \Delta C T}$ method was used for calculating the expression levels of the target genes, and $\beta$-actin was used as an endogenous control. The gene-specific primers used in this study are listed in Table S1. This assay was carried out in triplicate.

\subsection{Ultraviolet (UV) Stress Tolerance Assay}

The UV stress tolerance assay was carried out as described previously [41]. Briefly, about 100 conidia were spread on MMG plates and irradiated using the UV Spectrolinke XL-1000 UV crosslinker (Thomas Scientific, Swedesboro, NJ, USA). After irradiation, the plates were incubated at $37^{\circ} \mathrm{C}$ for $48 \mathrm{~h}$, and the colony numbers were counted. The survival rate was calculated by comparing the number of colonies in the UV-treated plate and the untreated plate.

\section{6. $\beta$-. Glucan Assay}

The amounts of $\beta$-1,3-glucan in conidia were measured by the Glucatell assay (Associates of Cape Cod, East Falmouth, MA, USA) as described previously [11,42]. Briefly, 2-day-old conidia from control and mutant strains were collected using double-distilled water. Conidia suspension was mixed with Glucatell reagent and incubated at $37^{\circ} \mathrm{C}$ for $30 \mathrm{~min}$. After incubation, diazo-reagents were added to stop the reaction, and the optical density was determined at $540 \mathrm{~nm}$.

\subsection{Sterigmatocystin Extraction and Thin-Layer Chromatography (TLC) Analysis}

The extraction of sterigmatocystin from 2-day-old conidia was conducted as described previously $[20,43]$. About $10^{9}$ conidia were mixed with $\mathrm{CHCl}_{3}$ and $0.5 \mathrm{~mm}$ zirconia/silica beads (RPI, Mt. Prospect, IL, USA) and disrupted using a Mini-Beadbeater (BioSpec Products, Inc., Bartlesville, OK, USA). After centrifugation, the organic phase was transferred to new vials and evaporated. Each sample was resuspended in $\mathrm{CHCl}_{3}$, spotted onto a TLC silica plate (Kiesel gel 60, $0.25 \mathrm{~mm}$; Merck, Kenilworth, NJ, USA), and resolved in toluene/ethyl acetate/acetic acid $(8: 1: 1, \mathrm{v} / \mathrm{v})$. The TLC plates were treated with $1 \%$ aluminum hydroxide hydrate (Sigma, St. Louis, MO, USA). The images of the TLC plates were captured after UV exposure $(366 \mathrm{~nm})$. The spot intensities of sterigmatocystin were quantified using ImageJ software.

\subsection{Statistical Analysis}

The statistical differences between control and $\triangle h b x B$ strains were evaluated by Student's unpaired $t$-test. The mean \pm standard deviation are shown. $p<0.05$ was considered significant.

\section{Results}

\subsection{Regulatory Role of $\mathrm{HbxB}$ in Conidia}

A previous study demonstrated that $\mathrm{HbxB}$ governs conidial viability, conidial trehalose biosynthesis, and stress response in conidia [34]. On the basis of these results, we hypothesized that $\mathrm{HbxB}$ is a transcription factor that can regulate the mRNA expression of a variety of genes in conidia. To test this hypothesis, RNA-seq analysis using control and $\triangle h b x B$ mutant conidia were conducted. The transcriptomic analysis results found that a 
total of 6230 genes were differentially expressed between control and $\triangle h b x B$ mutant conidia (fold change $>2.0 ; \mathrm{q}<0.05$; Figure S1). The mRNA levels of 3202 genes were upregulated, and the transcripts of 3028 genes were downregulated in $\triangle h b x B$ mutant conidia compared to control strain.

To further elucidate the regulatory role of $\mathrm{HbxB}$, we performed GO functional enrichment analysis using RNA-seq results and the ASPGD platform [36]. GO analysis revealed that up-regulated DEGs were enriched in mainly "carbohydrate metabolic process," "oxidoreductase activity," "cellular amino acid metabolic process," "secondary metabolic process," "translation," and "cell wall" (Figure 1A). The downregulated genes were mainly associated with "response to stress," "organelle organization," "response to chemical," "protein binding," and "endomembrane system" (Figure 1A).

A

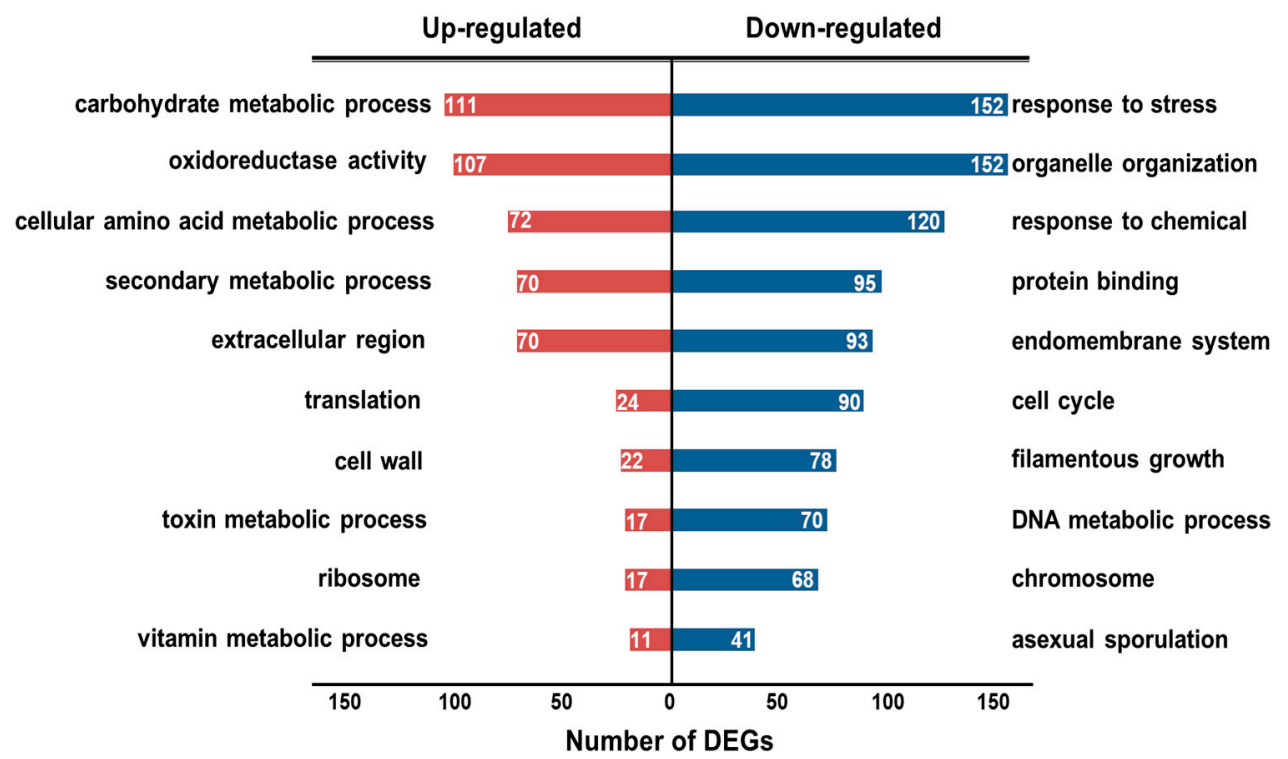

B

\section{Trehalose biogenesis genes}

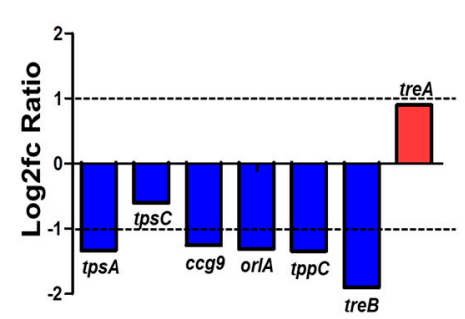

C

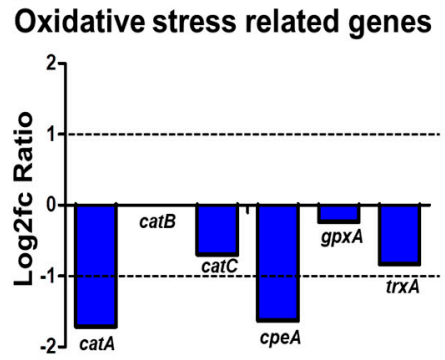

D

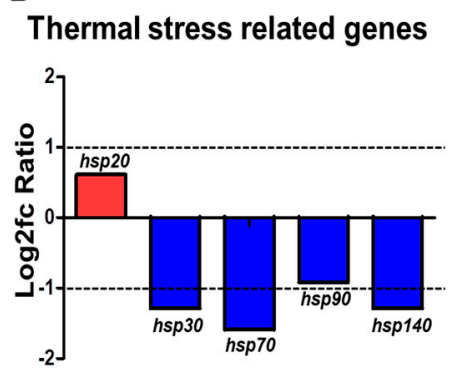

Figure 1. Transcriptomic analysis in $h b x B$ deletion mutant conidia. (A) Gene ontology (GO) term enrichment analysis of upregulated and downregulated genes in $h b x B$ deletion mutant conidia. (B-D) mRNA expression of genes associated with trehalose biogenesis $(\mathbf{B})$, oxidative stress response $(\mathbf{C})$, and thermal stress response $(\mathbf{D})$ in $h b x B$ deletion mutant conidia.

A previous study reported that $\mathrm{hbxB}$ deletion decreases the trehalose content and stress tolerance in conidia [34], suggesting that the mRNA expression of the related genes can also be affected. Therefore, the mRNA levels of genes associated with trehalose biosynthesis and response to oxidative and thermal stresses were evaluated. As shown in Figure 1B, the expression of $\operatorname{tps} A, \operatorname{orl} A$, and $\operatorname{tps} C$, which are involved in trehalose biosynthesis [44], was decreased. In addition, the transcript levels of genes associated with oxidative and thermal stress response were decreased (Figure 1C). The RNA-seq results were verified by 
qRT-PCR analysis (Figure S2). Overall, these transcriptomic results supported the reason why and how $h b x B$ deletion affects conidial phenotypes.

\subsection{Function of HbxB in UV Stress Response}

As shown in Figure 1A, many genes associated with stress response were downregulated in $h b x B$ mutant conidia. The list of these genes was screened, and several genes associated with radiation and UV stress response were downregulated (Figure $2 \mathrm{~A}-\mathrm{C}$ ), suggesting that $h b x B$ deletion can also affect the UV stress tolerance. To confirm this, we irradiated conidia of control, $\triangle h b x B$, and $C^{\prime} h b x B$ strains using a UV crosslinker. As shown in Figure 2D, the resistance of $\triangle h b x B$ conidia to UV stress was less than those of control and $C^{\prime} h b x B$ conidia. Taken together, these results demonstrated that $H b x B$ is required for an appropriate response to UV and other environmental stresses.

A

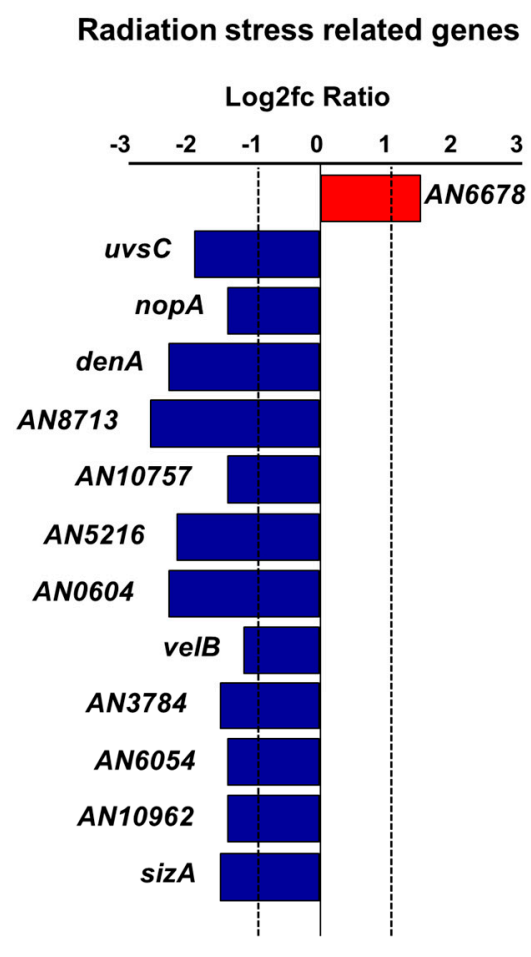

B

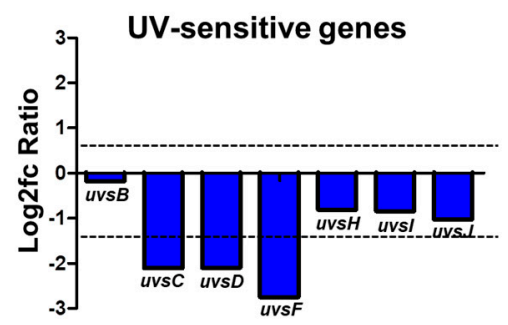

C

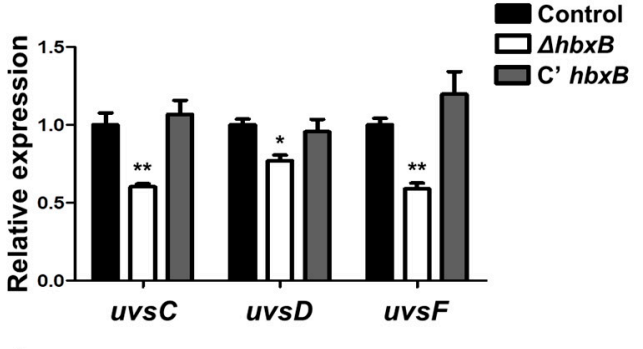

D

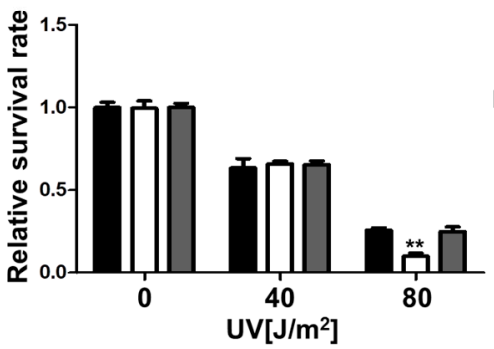

Figure 2. Role of $h b x B$ on UV stress tolerance in Aspergillus nidulans conidia. (A-C) mRNA expression of genes associated with radiation stress gene clusters in $h b x B$ deletion mutant conidia $(p<0.05, \log 2 \mathrm{fc}>1.0)$. (B) mRNA levels of genes involved in UV-sensitive gene clusters in $h b x B$ deletion mutant conidia. (C) mRNA expression of $u v s C$, $u v s D$, and $u v s F$ in control (TNJ36), $\triangle h b x B$ (TSH1.1), and $C^{\prime} h b x B$ (TSH7.1) strain conidia were verified by qRT-PCR analysis. ${ }^{*} p<0.05 ;{ }^{* *} p<0.01$, differences between control and $\Delta h b x B$ conidia. (D) UV sensitivity of control (TNJ36), $\Delta h b x B$ (TSH1.1), and C' $h b x B$ (TSH7.1) strain conidia. ${ }^{* *} p<0.01$, differences between control and $\Delta h b x B$ conidia.

\subsection{Function of HbxB in UV Stress Response}

RNA-seq analysis results showed that the genes involved in cell wall integrity were also affected by $h b x B$ deletion (Figure $1 \mathrm{~A}$ ). Among them, 12 genes associated with $\beta$-glucan degradation were upregulated in $\triangle h b x B$ conidia (Table 1 ; Figure 3A). To test the phenotypic change according to the alteration of gene expression, we examined the amount of $\beta$ glucan in conidia. As shown in Figure 3B, $\beta$-glucan production was decreased in the $\Delta h b x B$ mutant conidia compared to control and $C^{\prime} h b x B$ conidia. These results demonstrated that $\mathrm{HbxB}$ affects the production of $\beta$-glucan in conidia by regulating the mRNA expression of $\beta$-glucan degradation-related genes 
Table 1. Differentially expressed genes (DEGs) associated with cell wall integrity in $\Delta h b x B$ conidia.

\begin{tabular}{|c|c|c|}
\hline $\begin{array}{c}\text { Category (Number of Genes } \\
\text { in the Category) }\end{array}$ & $\begin{array}{c}\text { Upregulated Genes in } \Delta h b x B \\
\text { Conidia }\end{array}$ & $\begin{array}{c}\text { Downregulated Genes in } \\
\Delta h b x B \text { Conidia }\end{array}$ \\
\hline$\beta$-Glucan biosynthesis (12) & $\begin{array}{c}\operatorname{gelB}, \operatorname{crhD}, \operatorname{sun} A \\
\operatorname{bglA}, \operatorname{bglB}, \operatorname{bgl} \mathrm{g}, \operatorname{bgl} \mathrm{H}, \operatorname{bgl} \mathrm{L}\end{array}$ & gelD \\
\hline$\beta$-Glucan degradation (41) & $\begin{array}{c}\operatorname{crh} B, \operatorname{crh} D, \operatorname{egl} A, \operatorname{exgB}, \operatorname{exg} C, \\
\operatorname{exg} E, A N 3883\end{array}$ & - \\
\hline Chitin biosynthesis (17) & chsF & chs7 \\
\hline Chitin degradation (23) & chiC, AN0221, AN0299 & nag A, AN12280, AN8999 \\
\hline
\end{tabular}

A

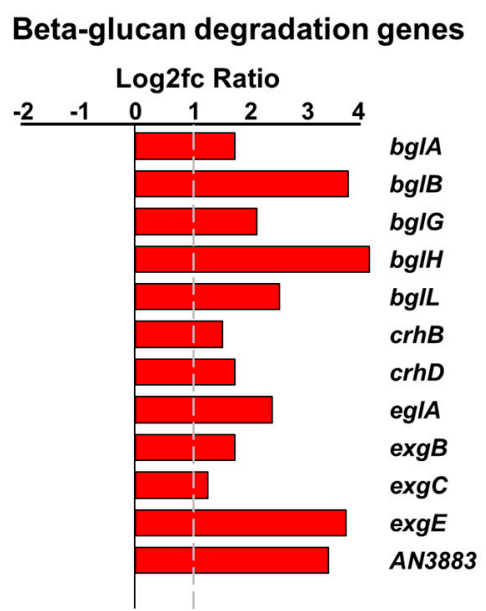

B

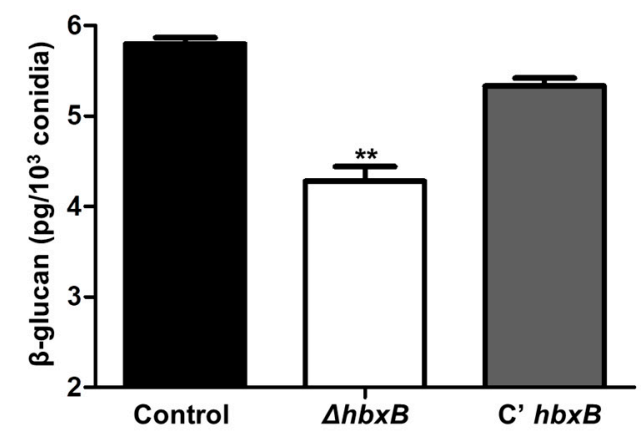

Figure 3. Role of $h b x B$ on $\beta$-glucan degradation in A. nidulans conidia. (A) mRNA expression of genes associated with $\beta$-glucan degradation in $h b x B$ deletion mutant conidia. (B) Amount of $\beta$-glucan in control (TNJ36), $\Delta h b x B$ (TSH1.1), and $C^{\prime}$ $h b x B$ (TSH7.1) strain conidia. ${ }^{* *} p<0.01$, differences between control and $\Delta h b x B$ conidia.

\subsection{HbxB Affects Sterigmatocystin Production in Conidia.}

As mentioned above, $h b x B$ deletion affects gene expression for secondary metabolic processes (Figure 1A). Among the secondary metabolite gene clusters, the mRNA expression of several genes involved in the sterigmatocystin gene cluster was upregulated in the $\triangle h b x B$ mutant conidia compared to control and $C^{\prime} h b x B$ conidia (Figure $4 \mathrm{~A}$ ). In addition, $\triangle h b x B$ conidia had a higher amount of sterigmatocystin than control and $C^{\prime} h b x B$ conidia (Figure $4 \mathrm{~B}, \mathrm{C}$ ). These results suggested that $\mathrm{HbxB}$ is essential for the proper production of sterigmatocystin in conidia. 
A

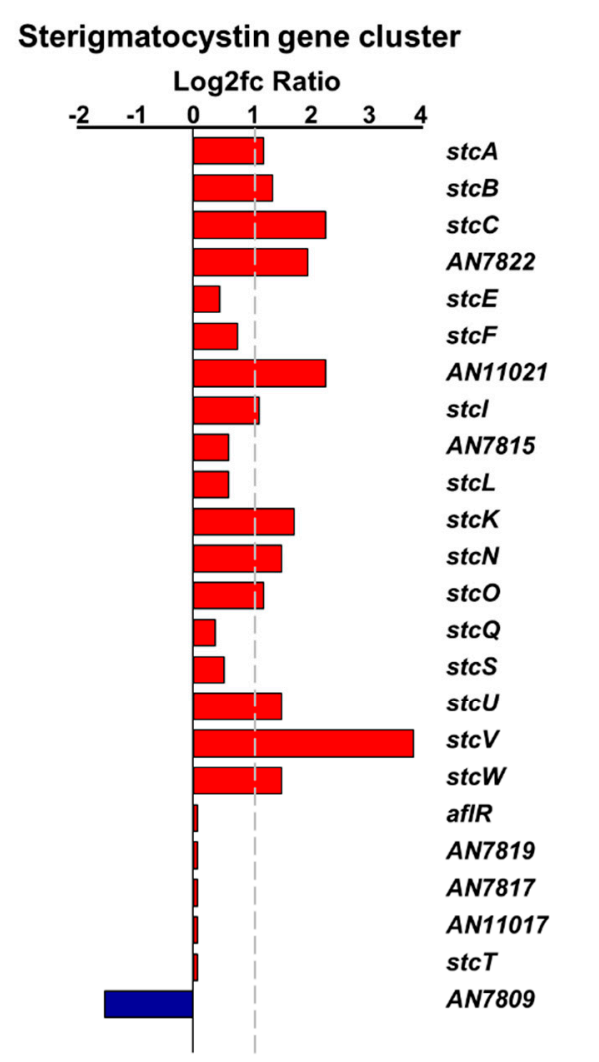

B

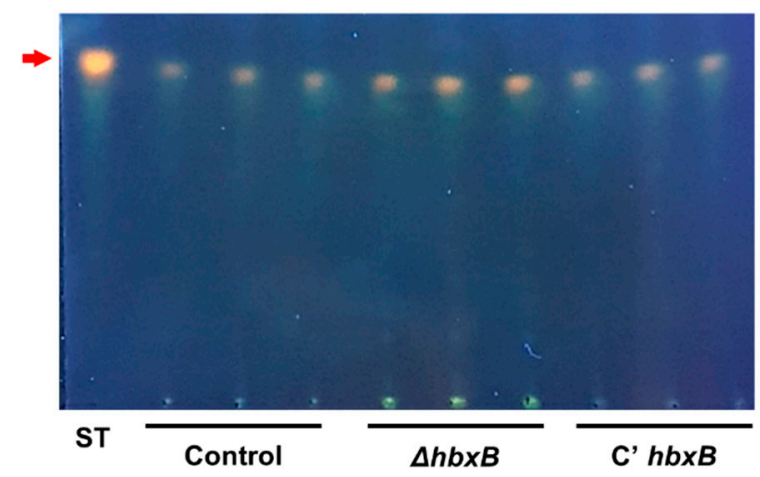

C

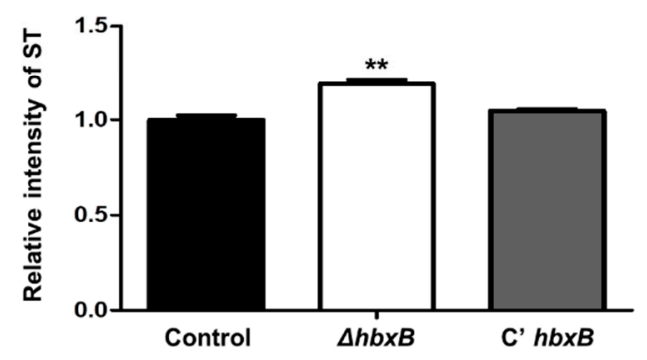

Figure 4. Role of $h b x B$ for sterigmatocystin production in $A$. nidulans conidia. (A) mRNA expression of genes associated with the sterigmatocystin gene in $h b x B$ deletion mutant conidia was verified by RNA-sequencing (RNA-seq) analysis. (B) Thin-layer chromatography (TLC) images of sterigmatocystin from control (TNJ36), $\Delta h b x B$ (TSH1.1), and C' $h b x B$ (TSH7.1) strain conidia. (C) Relative intensity of sterigmatocystin in (B) using ImageJ software. ${ }^{* *} p<0.01$, differences between control and $\Delta h b x B$ conidia.

\section{Discussion}

Homeobox proteins are conserved in most filamentous fungi and play diverse roles in fungal development and metabolisms [21,26]. Most Aspergillus species contain eight homeobox proteins, of which $\mathrm{HbxA}$ (or $\mathrm{Hbx} 1$ ) has been mainly studied [31,33]. In three Aspergillus species, including Aspergillus nidulans, Aspergillus fumigatus, and Aspergillus flavus, $h b x A$ (or $h b x 1$ ) deletion affects hyphal growth, conidiophore formation, and secondary metabolite production. The roles of $h b x A$ in asexual development has been demonstrated in other fungi, such as Fusarium graminearum, Magnaporthe oryzae, and Ustilaginoidea virens, suggesting that the roles of $\mathrm{HbxA}$ (or HbxA orthologs) are conserved in fungal development $[25,27,45]$. Unlike HbxA, the function of other homeobox domain-containing proteins including $\mathrm{HbxB}$ (or $\mathrm{HbxB}$ orthologs) has not been studied well in other fungi. Recently, our study revealed the role of $\mathrm{HbxB}$ in A. nidulans [34]. $\mathrm{HbxB}$ acts as a key regulator for the balance between asexual and sexual development in $A$. nidulans. In this study, we first reported the function of $\mathrm{HbxB}$ in spores through the transcriptomic and phenotypic analyses. These results can provide an insight into the basic knowledge about the function of the $\mathrm{HbxB}$ orthologs in other fungal species.

One of the important findings in this study is that $\mathrm{HbxB}$ is important for response to various stresses in conidia. RNA-seq results found that the mRNA expression of approximately 150 genes associated with stress response was downregulated in $\triangle h b x B$ conidia (Figure 1). These are associated with response to oxidative (cat $A, \operatorname{cpe} A$, and $\operatorname{tr} x A$ ), thermal (hsp30, hsp70, and hsp140), radiation (nopA, $\operatorname{den} A, v e l B$, and $\operatorname{sizA})$, and UV (uvsC, uvsD, and $u v s F$ ) stresses (Figures 1 and 2). This decreased mRNA expression of stress-related 
genes might affect the phenotype and increase susceptibility to various stresses, including thermal, oxidative, and UV stresses. In addition, decreased mRNA expression of trehalose biosynthesis genes and the amount of trehalose in $\Delta h b x B$ conidia can also affect the response to various stresses. These results supported the idea that $\mathrm{HbxB}$ is a key controller for the various stress responses in conidia. Although we found that $\mathrm{HbxB}$ affects mRNA expression of stress-related genes, the detailed molecular mechanism of $\mathrm{HbxB}$ has not been studied yet. Moreover, the genetic relationship between $\mathrm{HbxB}$ and other regulators involved in conidial stress response has not been studied. In conidia, the high-osmolarity glycerol (HOG) pathway and the velvet proteins control conidial stress tolerance in A. nidulans $[4,46]$. We can speculate that $\mathrm{HbxB}$ cross-talk with the HOG pathway or the velvet regulators for regulating mRNA expression of genes involved in conidial stress response. Further research will be needed to illuminate how conidial stress response is precisely regulated by these regulators.

Another finding in this study is that $\mathrm{HbxB}$ is involved in gene expression related to secondary metabolite gene clusters (Figure 4). In particular, $\mathrm{HbxB}$ can function as a negative regulator for sterigmatocystin production. The mRNA levels of several sterigmatocystin biosynthesis genes and the amount of sterigmatocystin were increased in $\Delta h b x B$ conidia. However, this result is the opposite of a previous result. In dark conditions for sexual development, $h b x B$ deletion decreased sterigmatocystin production and the mRNA levels of aflR, encoding an activator of the sterigmatocystin gene cluster [34]. It was speculated that the function of $\mathrm{HbxB}$ works differently depending on the temporal or cell type-specific regulation, and additional studies are needed to reveal this.

Overall, this study suggests that $\mathrm{HbxB}$ has a multi-functional role in fungal development and metabolism in $A$. nidulans. During the developmental process, $\mathrm{HbxB}$ regulates the balance between asexual and sexual development. In conidia, $\mathrm{HbxB}$ regulates the mRNA levels of genes associated with stress response, $\beta$-glucan biosynthesis, trehalose biosynthesis, and secondary metabolism, thereby governing conidial stress response, primary and secondary metabolism, and conidial maturation (Figure 5). Although $\mathrm{HbxB}$ has been found to affect the transcription of thousands of genes, the direct targets of $\mathrm{HbxB}$ and the detailed molecular mechanism of $\mathrm{HbxB}$ are still unknown. It should be required for understanding conidiogenesis in A. nidulans.

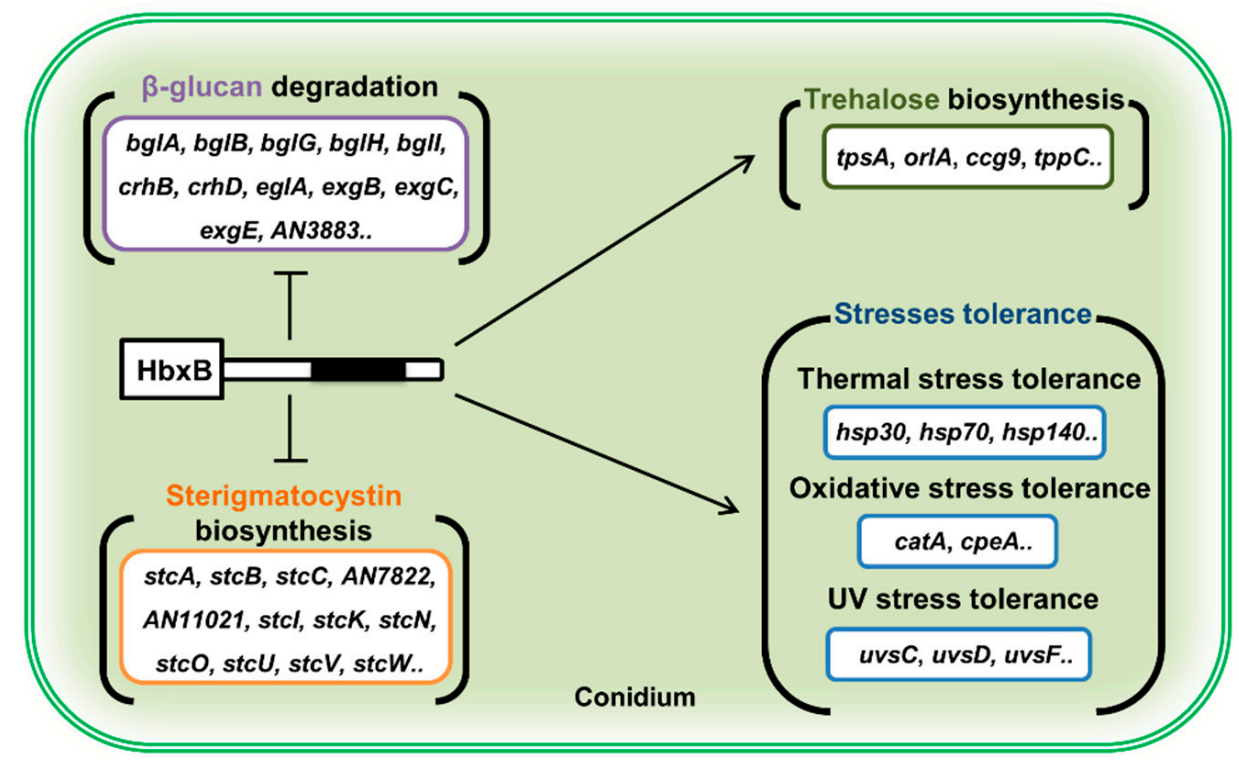

Figure 5. Proposed model depicting the role of $\mathrm{HbxB}$ in conidium (see the Discussion section). 
Supplementary Materials: The following are available online at https://www.mdpi.com/2076 $-2607 / 9 / 1 / 144 / s 1$ : Figure S1. Heat map images of DEGs between control and $\Delta h b x B$ conidia (fold change $>2.0 ; q<0.05$ ). Figure S2. Levels of genes involved in trehalose biosynthesis (A) and oxidative stress response (B) were verified by qRT-PCR analysis. ${ }^{*} p<0.05 ;{ }^{* *} p<0.01$; ${ }^{* * *} p<0.001$, differences between control and $\triangle h b x B$ conidia. Table S1. Oligonucleotides used in this study.

Author Contributions: Conceptualization, H.-S.P.; methodology, validation, formal analysis, and data curation, S.-H.S. and Y.-E.S.; writing—original draft preparation and editing, M.-K.L. and H.-S.P.; supervision, project administration, and funding acquisition, M.-K.L. and H.-S.P. All authors have read and agreed to the published version of the manuscript.

Funding: H.-S.P. was supported by a National Research Foundation of Korea (NRF) grant (NRF2020R1C1C1004473) funded by the Korean Government. M.-K.L. was supported by the KRIBB Research Initiative Program.

Institutional Review Board Statement: Not applicable.

Informed Consent Statement: Not applicable.

Data Availability Statement: All RNA-seq data files are available from the National Center for Biotechnology Infor-mation BioProject database (PRJNA681980).

Acknowledgments: We thank lab members for critically reading this manuscript.

Conflicts of Interest: The authors have no conflict of interest to declare.

\section{References}

1. Adams, T.H.; Wieser, J.K.; Yu, J.-H. Asexual sporulation in Aspergillus nidulans. Microbiol. Mol. Biol Rev. 1998, 62, 35-54. [CrossRef] [PubMed]

2. Park, H.-S.; Yu, J.-H. Genetic control of asexual sporulation in filamentous fungi. Curr. Opin. Microbiol. 2012, 15, 669-677. [CrossRef] [PubMed]

3. Beauvais, A.; Latge, J.P. Special Issue: Fungal Cell Wall. J. Fungi 2018, 4, 91. [CrossRef] [PubMed]

4. Hagiwara, D.; Sakamoto, K.; Abe, K.; Gomi, K. Signaling pathways for stress responses and adaptation in Aspergillus species: Stress biology in the post-genomic era. Biosci. Biotechnol. Biochem. 2016, 80, 1667-1680. [CrossRef] [PubMed]

5. Gow, N.A.R.; Latge, J.P.; Munro, C.A. The Fungal Cell Wall: Structure, Biosynthesis, and Function. Microbiol. Spectr. 2017, 5. [CrossRef]

6. Galagan, J.E.; Calvo, S.E.; Cuomo, C.; Ma, L.J.; Wortman, J.R.; Batzoglou, S.; Lee, S.I.; Basturkmen, M.; Spevak, C.C.; Clutterbuck, J.; et al. Sequencing of Aspergillus nidulans and comparative analysis with A. fumigatus and A. oryzae. Nature 2005, 438, 1105-1115. [CrossRef]

7. McCluskey, K.; Baker, S.E. Diverse data supports the transition of filamentous fungal model organisms into the post-genomics era. Mycology 2017, 8, 67-83. [CrossRef]

8. Ojeda-Lopez, M.; Chen, W.; Eagle, C.E.; Gutierrez, G.; Jia, W.L.; Swilaiman, S.S.; Huang, Z.; Park, H.S.; Yu, J.H.; Canovas, D.; et al. Evolution of asexual and sexual reproduction in the aspergilli. Stud. Mycol. 2018, 91, 37-59. [CrossRef]

9. Ni, M.; Yu, J.H. A novel regulator couples sporogenesis and trehalose biogenesis in Aspergillus nidulans. PLoS ONE 2007, 2, e970. [CrossRef]

10. Park, H.S.; Ni, M.; Jeong, K.C.; Kim, Y.H.; Yu, J.H. The role, interaction and regulation of the velvet regulator VelB in Aspergillus nidulans. PLoS ONE 2012, 7, e45935. [CrossRef]

11. Park, H.S.; Man Yu, Y.; Lee, M.K.; Jae Maeng, P.; Chang Kim, S.; Yu, J.H. Velvet-mediated repression of beta-glucan synthesis in Aspergillus nidulans spores. Sci. Rep. 2015, 5, 10199. [CrossRef] [PubMed]

12. Wu, M.Y.; Mead, M.E.; Kim, S.C.; Rokas, A.; Yu, J.H. WetA bridges cellular and chemical development in Aspergillus flavus. PLoS ONE 2017, 12, e0179571. [CrossRef] [PubMed]

13. Wu, M.Y.; Mead, M.E.; Lee, M.K.; Ostrem Loss, E.M.; Kim, S.C.; Rokas, A.; Yu, J.H. Systematic Dissection of the Evolutionarily Conserved WetA Developmental Regulator across a Genus of Filamentous Fungi. mBio 2018, 9. [CrossRef] [PubMed]

14. Ahmed, Y.L.; Gerke, J.; Park, H.-S.; Bayram, O.; Neumann, P.; Ni, M.; Dickmanns, A.; Kim, S.C.; Yu, J.-H.; Braus, G.H.; et al. The velvet family of fungal regulators contains a DNA-binding domain structurally similar to NF-kappaB. PLoS Biol. 2013, 11, e1001750. [CrossRef] [PubMed]

15. Sewall, T.C.; Mims, C.W.; Timberlake, W.E. Conidium differentiation in Aspergillus nidulans wild-type and wet-white (wetA) mutant strains. Dev. Biol. 1990, 138, 499-508. [CrossRef]

16. Navarro, R.E.; Stringer, M.A.; Hansberg, W.; Timberlake, W.E.; Aguirre, J. catA, a new Aspergillus nidulans gene encoding a developmentally regulated catalase. Curr. Genet. 1996, 29, 352-359.

17. Hagiwara, D.; Asano, Y.; Yamashino, T.; Mizuno, T. Characterization of bZip-type transcription factor AtfA with reference to stress responses of conidia of Aspergillus nidulans. Biosci. Biotechnol. Biochem. 2008, 72, 2756-2760. [CrossRef] 
18. Hagiwara, D.; Takahashi, H.; Kusuya, Y.; Kawamoto, S.; Kamei, K.; Gonoi, T. Comparative transcriptome analysis revealing dormant conidia and germination associated genes in Aspergillus species: An essential role for AtfA in conidial dormancy. BMC Genomics 2016, 17, 358. [CrossRef]

19. Park, H.S.; Lee, M.K.; Kim, S.C.; Yu, J.H. The role of VosA/VelB-activated developmental gene vadA in Aspergillus nidulans. PLoS ONE 2017, 12, e0177099. [CrossRef]

20. Son, Y.E.; Park, H.S. Genome wide analysis reveals the role of VadA in stress response, germination, and sterigmatocystin production in Aspergillus nidulans conidia. Microorganisms 2020, 8, 1319. [CrossRef]

21. Gehring, W.J.; Affolter, M.; Burglin, T. Homeodomain proteins. Annu. Rev. Biochem. 1994, 63, 487-526. [CrossRef] [PubMed]

22. Gehring, W.J.; Qian, Y.Q.; Billeter, M.; Furukubo-Tokunaga, K.; Schier, A.F.; Resendez-Perez, D.; Affolter, M.; Otting, G.; Wuthrich, K. Homeodomain-DNA recognition. Cell 1994, 78, 211-223. [CrossRef]

23. Bobola, N.; Merabet, S. Homeodomain proteins in action: Similar DNA binding preferences, highly variable connectivity. Curr. Opin. Genet. Dev. 2017, 43, 1-8. [CrossRef] [PubMed]

24. Burglin, T.R.; Affolter, M. Homeodomain proteins: An update. Chromosoma 2016, 125, 497-521. [CrossRef] [PubMed]

25. Kim, S.; Park, S.Y.; Kim, K.S.; Rho, H.S.; Chi, M.H.; Choi, J.; Park, J.; Kong, S.; Park, J.; Goh, J.; et al. Homeobox transcription factors are required for conidiation and appressorium development in the rice blast fungus Magnaporthe oryzae. PLoS Genet. 2009, 5, e1000757. [CrossRef]

26. Vonk, P.J.; Ohm, R.A. The role of homeodomain transcription factors in fungal development. Fungal Biol. Rev. 2018, 32, 219-230. [CrossRef]

27. Yu, J.; Yu, M.; Song, T.; Cao, H.; Pan, X.; Yong, M.; Qi, Z.; Du, Y.; Zhang, R.; Yin, X.; et al. A Homeobox Transcription Factor UvHOX2 Regulates Chlamydospore Formation, Conidiogenesis, and Pathogenicity in Ustilaginoidea virens. Front. Microbiol. 2019, 10, 1071. [CrossRef]

28. Haber, J.E. Mating-type genes and MAT switching in Saccharomyces cerevisiae. Genetics 2012, 191, 33-64. [CrossRef]

29. Ghosh, A.K.; Wangsanut, T.; Fonzi, W.A.; Rolfes, R.J. The GRF10 homeobox gene regulates filamentous growth in the human fungal pathogen Candida albicans. FEMS Yeast Res. 2015, 15. [CrossRef]

30. Wangsanut, T.; Ghosh, A.K.; Metzger, P.G.; Fonzi, W.A.; Rolfes, R.J. Grf10 and Bas1 Regulate Transcription of Adenylate and One-Carbon Biosynthesis Genes and Affect Virulence in the Human Fungal Pathogen Candida albicans. mSphere 2017, 2. [CrossRef]

31. Cary, J.W.; Harris-Coward, P.; Scharfenstein, L.; Mack, B.M.; Chang, P.K.; Wei, Q.; Lebar, M.; Carter-Wientjes, C.; Majumdar, R.; Mitra, C.; et al. The Aspergillus flavus Homeobox Gene, $h b x 1$, is Required for Development and Aflatoxin Production. Toxins 2017, 9, 315. [CrossRef] [PubMed]

32. Cary, J.W.; Entwistle, S.; Satterlee, T.; Mack, B.M.; Gilbert, M.K.; Chang, P.K.; Scharfenstein, L.; Yin, Y.; Calvo, A.M. The Transcriptional Regulator Hbx1 Affects the Expression of Thousands of Genes in the Aflatoxin-Producing Fungus Aspergillus flavus. G3 (Bethesda) 2019, 9, 167-178. [CrossRef] [PubMed]

33. Satterlee, T.; Nepal, B.; Lorber, S.; Puel, O.; Calvo, A.M. The Transcriptional Regulator HbxA Governs Development, Secondary Metabolism, and Virulence in Aspergillus fumigatus. Appl. Environ. Microbiol. 2020, 86. [CrossRef] [PubMed]

34. Son, S.H.; Son, Y.E.; Cho, H.J.; Chen, W.; Lee, M.K.; Kim, L.H.; Han, D.M.; Park, H.S. Homeobox proteins are essential for fungal differentiation and secondary metabolism in Aspergillus nidulans. Sci. Rep. 2020, 10, 6094. [CrossRef]

35. Park, H.S.; Yu, J.H. Multi-copy genetic screen in Aspergillus nidulans. Methods Mol. Biol. 2012, 944, 183-190. [CrossRef]

36. Arnaud, M.B.; Chibucos, M.C.; Costanzo, M.C.; Crabtree, J.; Inglis, D.O.; Lotia, A.; Orvis, J.; Shah, P.; Skrzypek, M.S.; Binkley, G.; et al. The Aspergillus Genome Database, a curated comparative genomics resource for gene, protein and sequence information for the Aspergillus research community. Nucleic Acids Res. 2010, 38, D420-D427. [CrossRef]

37. Dobin, A.; Davis, C.A.; Schlesinger, F.; Drenkow, J.; Zaleski, C.; Jha, S.; Batut, P.; Chaisson, M.; Gingeras, T.R. STAR: Ultrafast universal RNA-seq aligner. Bioinformatics 2013, 29, 15-21. [CrossRef]

38. Trapnell, C.; Williams, B.A.; Pertea, G.; Mortazavi, A.; Kwan, G.; van Baren, M.J.; Salzberg, S.L.; Wold, B.J.; Pachter, L. Transcript assembly and quantification by RNA-Seq reveals unannotated transcripts and isoform switching during cell differentiation. Nat. Biotechnol. 2010, 28, 511-515. [CrossRef]

39. Anders, S.; Pyl, P.T.; Huber, W. HTSeq-a Python framework to work with high-throughput sequencing data. Bioinformatics 2015, 31, 166-169. [CrossRef]

40. Sun, J.; Nishiyama, T.; Shimizu, K.; Kadota, K. TCC: An R package for comparing tag count data with robust normalization strategies. BMC Bioinform. 2013, 14, 219. [CrossRef]

41. Sarikaya Bayram, O.; Bayram, O.; Valerius, O.; Park, H.-S.; Irniger, S.; Gerke, J.; Ni, M.; Han, K.H.; Yu, J.-H.; Braus, G.H. LaeA control of velvet family regulatory proteins for light-dependent development and fungal cell-type specificity. PLoS Genet. 2010, 6, e1001226. [CrossRef]

42. Odabasi, Z.; Mattiuzzi, G.; Estey, E.; Kantarjian, H.; Saeki, F.; Ridge, R.J.; Ketchum, P.A.; Finkelman, M.A.; Rex, J.H.; OstroskyZeichner, L. Beta-D-glucan as a diagnostic adjunct for invasive fungal infections: Validation, cutoff development, and performance in patients with acute myelogenous leukemia and myelodysplastic syndrome. Clin. Infect. Dis. 2004, 39, 199-205. [CrossRef]

43. Son, Y.E.; Cho, H.J.; Chen, W.; Son, S.H.; Lee, M.K.; Yu, J.H.; Park, H.S. The role of the VosA-repressed $d n j A$ gene in development and metabolism in Aspergillus species. Curr. Genet. 2020, 66, 621-633. [CrossRef] 
44. Thammahong, A.; Puttikamonkul, S.; Perfect, J.R.; Brennan, R.G.; Cramer, R.A. Central Role of the Trehalose Biosynthesis Pathway in the Pathogenesis of Human Fungal Infections: Opportunities and Challenges for Therapeutic Development. Microbiol. Mol. Biol. Rev. 2017, 81. [CrossRef]

45. Zheng, W.; Zhao, X.; Xie, Q.; Huang, Q.; Zhang, C.; Zhai, H.; Xu, L.; Lu, G.; Shim, W.B.; Wang, Z. A conserved homeobox transcription factor Htf1 is required for phialide development and conidiogenesis in Fusarium species. PLoS ONE 2012, 7, e45432. [CrossRef]

46. Park, H.S.; Yu, J.H. Velvet Regulators in Aspergillus spp. Microbiol. Biotechnol. Lett. 2017, 44, 409-419. [CrossRef] 